\title{
|WTEREFAEE TEENOLÓGCA
}

\section{CAFÉ E SEUS BENEFICIOS}

\section{COFFEE AND IT'S BENEFITS}

\author{
Maria Eduarda Oliverio Ramalho - meoliramalho@ hotmail.com \\ Nathalia Maria Soares - nathalia.soares@ fatectq.edu.br \\ Faculdade de Tecnologia de Taquaritinga (FATEC) - SP - Brasil
}

DOI: 10.31510/infa.v15i1.356

\section{RESUMO}

Este artigo científico relata sobre o café, no seu âmbito histórico e conceitual, buscando realizar a análise de seus benefícios e malefícios para a saúde do consumidor. Para tal pesquisa, foi realizada uma revisão bibliográfica, a qual está baseada na Associação Brasileira da Indústria do Café (ABIC) e em pesquisas médicas; ambas apresentam, em suas teorias, todos os seus componentes químicos do café, e enquadramento deste dentro do cotidiano do ser humano. Essa pesquisa tem o objetivo de mostrar aos apreciadores dessa bebida - consumida em aproximadamente 21,5 milhões de sacas no Brasil de acordo com a Embrapa - que tomar seu cafezinho, com moderação, pode lhe trazer alguns benefícios.

Palavras-chave: Café. Benefícios. Componentes químicos.

\begin{abstract}
This paper reports on coffee, in its historical and conceptual scope, aiming to carry out the analysis of its benefits and harms for the health of the consumer. For this research, a bibliographic review was conducted, based on the Brazilian Coffee Industry Association (ABIC) and on medical research; both present in their theories, all the coffee's chemical components, and its importance in the daily life of the human being. This research aims to show to the fans of this drink - consumed in approximately 21.5 million bags in Brazil according to Embrapa - that having their coffee, in moderation, can bring them some benefits
\end{abstract}

Keywords: Coffee. Benefits. Chemical Components.

\section{INTRODUÇÃO}

O café é uma das bebidas mais consumidas no mundo, e no Brasil, segundo dados da Associação Brasileira da Indústria de Café - ABIC, o mercado brasileiro representa $31 \%$ da demanda mundial, com um consumo de $5.10 \mathrm{~kg}$ de café torrado por habitante/ano, ou seja, aproximadamente 85 L para cada brasileiro (ABIC, 2018). 


\section{WTERPHEGETEENOLOGGCA}

Pode-se destacar, que nos dias de hoje, especialistas da área da saúde, tem incentivado o consumo de café. Avanços nas ciências, como programas de incentivo ao café, cooperam para desvendar velhos preconceitos envolvendo o café e a cafeína nas alterações cruéis para o organismo. Em uma pesquisa feita por Almeida (2003) findaram que não se deve considerar como fator de risco para doenças, como, doenças cardiovasculares, câncer de bexiga, de pâncreas e de intestino, o consumo de café e cafeína. O estudo mostrou que o café é um motivador da redução do risco de algumas espécies de câncer, devido a substâncias antioxidantes, anticarcinogênicas e antiteratogênicas naturalmente presentes no café ou formadas durante o seu processamento.

De acordo com Lima (2007), o consumo em quantias reduzidas, de em média até quatro xícaras por dia, transforma o cérebro mais concentrado e apto para exercer suas atividades intelectuais, reduz a ocorrência de apatia e depressão e fomenta a memória, atenção e concentração e, consequentemente, beneficia a atividade intelectual, tornandose apropriado à todas as idades, aliais crianças e adolescentes.

Consagradamente, para se qualificar comercialmente a qualidade do café as técnicas são respaldadas, de preferência, no aspecto físico e na "prova de xícara". Apesar disso, as peculiaridades essenciais e as predileções do consumidor brasileiro em relação à bebida café são pouco aparentes (Monteiro, 2002). Os consumidores passaram a ser mais rigorosos ao consumir café, fazendo com que as indústrias e órgãos pertencentes à produção e processamento do café ficassem mais vigilantes.

Estudos realizados pela ABIC (2018), revela que o café desde 1997 até os dias atuais é consumido para reanimar, é ótimo para ser consumir no serviço e para oferecer em acontecimentos sociais, sendo consumido por força do hábito, e pelo prazer e em decorrência do seu sabor e aroma.

E assim, diante do amplo e crescente mercado de café no Brasil que em 2017 foi estimado em 21,5 milhões de sacas, que correspondem a aproximadamente 1,07 milhão de toneladas e com esse volume, o nosso País se destaca como segundo maior consumidor de café em nível mundial, seja ele na forma expressa, cafezinho, encapsulado e similares (EMBRAPA,2017) E este artigo, tem por objetivo, analisar e explicar alguns dos benefícios desta bebida, e eventualmente mencionar seus malefícios. 


\section{INTEREAGEETECHOLÓGICA}

\section{COMPOSIÇÃO QUIMÍCA DO CAFÉ}

A diversidade genetica, as condições ambientais, como altitude, temperatura e umidade e o processamento pós colheita pode intervir na composição do grão de café cru (Garrett, 2013 e Taveira, 2015).

Os principais constituintes do grão de café cru são os carboidratos solúveis que possuem o teor é de $6-12,5 \%$, e corresponde a monossacarídeos (frutose, glucose, galactose, arabinose), oligossacarídeos (sucrose, rafinose, estaquiose) e polissacarídeos (polímeros de galactose, manose e arabinose), já os insolúveis são a celulose e hemicelulose, dois polissacarídeos insolúveis, apresentam um teor de 41-43\%, e 5-10\% respetivamente. (Arya, 2007, p.47-51).

De acordo com Joet (2010,p.118-693) a composição química de grão cru de Coffea arabica L. e C. canephora var. Robusta são:

Tabela 1. Composição química de grão cru

\begin{tabular}{c|c|c}
\hline Componente & Café Arabica $(\%)$ & Café Robusta $(\%)$ \\
\hline Cafeína & $0,7-1,4$ & $1,2-2,4$ \\
\hline Trigonelina & $1,0-1,2$ & $0,6-0,7$ \\
\hline Minerais & $3-4,2$ & $3-4,2$ \\
\hline Lignina & $1-3$ & $1-3$ \\
\hline Proteínas & $11,0-13,0$ & $11,0-13,0$ \\
\hline Amino ácidos livres & $0,2-0,8$ & $0,2-0,8$ \\
\hline Óleos & $7,7-16,0$ & $7,7-16,0$ \\
\hline Ceras & $0,2-0,3$ & $0,2-0,3$ \\
\hline Ácidos clorogênicos totais & $3,5-7,3$ & $7,0-14,0$ \\
\hline Ácidos alifáticos não voláteis & $2-2,9$ & $1,3-2,2$ \\
\hline Ácidos voláteis & 0,1 & 0,1 \\
\hline Carbohidratos solúveis & $9-12,5$ & $6,0-11,5$ \\
\hline Polissacarídeos insolúveis & $46-53$ & $34-44$ \\
\hline
\end{tabular}

Fonte. Joet. Influence of environmental factors, wet processing and their interactions on the biochemical composition of green Arabica coffee beans (2010).

No grão de café cru, é possível encontrar muitos compostos nitrogenados não proteicos, como por exemplo, cafeína $(0,7-1,4 \%)$, uma metilxantina com propriedades estimulantes do sistema nervoso central e também encontram descrições na literatura sobre traços de teofilina e teobromina (Belitz, 2009).

Complementarmente o café contém uma vitamina do complexo B, a niacina, e, em quantidade superior que todos os demais componentes, os ácidos clorogênicos, na proporção de 7 a $10 \%$, isto é, 3 a 5 vezes mais que a cafeína (Lima, 2003) 


\section{WTERPHECETEENOLOGGCA}

Também pode-se encontrar no grão de café além de uma grande variedade de minerais como potássio, magnésio, cálcio, sódio, ferro, manganês, rubídio, zinco, cobre, estrôncio, cromo, vanádio, bário, níquel, cobalto, chumbo, molibdênio, titânio e cádmio (Turgo, 2003).

Além disso, temos também, a composição da bebida café, onde os componentes químicos do grão de café definem a qualidade da bebida tanto do ponto de vista sensorial quanto do ponto de vista de saúde do consumidor.

Abordando a análise sensorial, é de se considerar que nenhuma das particulariedades da bebida se deva a um ou outro componente químico, mas sim a uma associação entre eles, que age sobre a percebismo do consumidor (Lima, 2007)

O amagor, a adstringência e o gosto de mofodo da bebida café se da devido ao nível de concentração de ácidos clorogênicos e das proporções em que eles se encontram no café, porém, há experiências que mostram, contrariamente ao que se relatou acima, dizendo que a cafeína tem pouco efeito no amargor da bebida (Salva, 2007).

A sacarose e a atrigonelina, são os composto de maior abundancia encontrados no café, e estas, são substancias que estão demasiadamente associadas com a composição do aroma da infusão (Lima, 2013)

$\mathrm{O}$ aspectos mais viscoso da bebida café, se da, por meio de uma classe chamada polissacarídeos, assim como a proteina que está integrada na composição do café (Lima et al, 2013)

Existem referências que o gosto de madeira conferido aos cafés mais antigos, se da por variações nas concentrações de ácidos graxos e diterpenos livres, produzidos no périodo da estocagem. A ação dos lipídeos se faz sentir, também, na retenção de aroma em café torrado (Lima et al, 2007).

A acidez atribuida a bebida café, esta relacionado ao compomente ácido fosfárico.

Nos tempos passados, se conferia diversos atributos indignos ao café do ponto de vista de saúde do seu consumidor. Buscava-se, por exemplo, associar enfermidades estomacais, intestinais, cardíacas e osteoporose, entre outras males, ao hábito de tomar café. Nos dias de hoje ja se sabe, que quando ingerida sem abusos, a infusão de café torrado reúne inúmeras atributos benéficos para a saúde humana. Pela torração, a trigonelina do café verde, por exemplo, se transforma em ácido nicotínico e nicotinamida, 


\title{
INTEREFGEETECHOLLGGCA
}

duas formas de vitamina B3. Quando o café é torrado, os ácidos clorogênicos também se modificam e dão origem a produtos com elevado poder antioxidante, tendo também ele próprio essa atividade em intensidade moderada. Atividades antioxidantes são atribuídas também às melanoidinas, um conjunto de substâncias cuja quase totalidade ainda não foi identificada, e que se formam durante a torração (Salva et al, 2007).

\section{BENEFICIOS DO CAFÉ}

Há inumeros trabalhos e pesquisas novas realizados com cientistas e pesquisadores renomados, que visam expandir os entendimentos sobre o café e seus beneficifios, demonstrando que o consumo periódico e balanceado de um ótimo café, evita sonolência, combate o stress, é rico em antioxidantes, ajuda na digestão, é amigo do fígado, melhora os níveis de atenção, bom para o diabetes tipo 2, faz bem para o coração, não causa problemas gástricos, bom para a memória, bom para o humor e estimulador da inteligência (EMBRAPA, 2011). Além do que, pode precaver: o Alzheimer, cálculos da vesícula, a obesidade, câncer, a depressão e Parkinson.

De acordo com a Associação brasileira da indústria de café:

\begin{abstract}
"a depressão é um condição independente de risco cardiovascular para homens e estudos modernos avaliam o papel protetor de medicamentos antidepressivos e hábitos alimentares. O consumo diário de doses moderadas de café torrado adequadamente pode ser benéfico na prevenção da depressão/DCV por conter, em quantidades superiores às de cafeína (1-2\%), compostos quinídeos derivados dos ácidos clorogênicos (2-4\%) com ação antioxidante, além de potente ação antagonista opióide (tipo naltrexona) e efeito inibidor da recaptação de adenosina. (ADIC,2018)."
\end{abstract}

Também tem se notado evidencias do efeito do café na prevençao da diabetes tipo 2, devido à enorme quantia de antioxidantes existente no café, como o ácido clorogênico e tocoferóis, assim como minerais, entre eles os magnésio, os quais têm sido apontados como importantes para melhorar a sensibilidade à insulina e metabolismo da glicose, porém essa ajuda apenas se dá quando a bebida é consumida com moderação (quatro xicaras diarias), pois o seu excesso e o seu consumo durante as refeições pode elevar os niveis de glicose e os niveis de insulina (Krolow, 2011).

Com isso, existem relatos de que o consumo de café habitualmente mostra efeito de diminuição de até $80 \%$ o progresso do Mal de Parkinson, bem como, também está relacionado a redução das crises de asma, do qual a resultância benéfica em ambas é 
destinada ao consumo de cafeína (EMBRAPA, 2011).

Neste mesmo contexto, vale lembrar que no caso das crianças há sempre a polêmica, se o café pode ou não, porém o café com leite é a bebida mais adequada e com mais nutrientes para as crianças, sendo assim, o consumo moderado e diário do café, pode diminuir os indices de depressão, estimula o sistema de vigília, atenção e concentração, podendo ajudar no aprendizado escolar, pois deixa o cérebro mais atento e capaz de suas atividades intelectuais, diminui a incidência de apatia e depressão e estimula a memória, atenção e concentração, melhorando a atividade intelectual normal (ABIC, 2018).

No decorrer dos estudos e de acordo com Bartutti (2016), o comsumo de 2 a 3 xícaras de café, aparentemente pode ser uma estrategia interessante para reduzir as chances de cirose hepática e consequentemente o câncer de figado.

No entanto a Organização Mundial da Saúde (OMS, 2017), bebidas ingeridas muito quentes podem acarretar câncer de esôfago.

Já no caso dos atletas, segundo Lima, (2013):

\begin{abstract}
"Em atletas que tomam café diariamente durante os treinos, na dose mínima de 4 xícaras, a cafeína atua como estimulante do sistema nervoso e, por retardar a sensação de fadiga, propicia o fortalecimento dos músculos. Ajuda, ainda, na mobilização de substratos de energia para o trabalho muscular. O resultado é mais rendimento físico e queima de gordura como fonte de energia em vez de açúcares encontrados nos carboidratos."
\end{abstract}

Pois é possível imaginar que os ácidos clorogênicos/quinídeeos do café bloqueariam os receptores que são estimulados pelas endorfinas, peptídeos opióides cerebrais. Isto faria com que os neurônios do cérebro aumentassem sua descarga de endorfinas para trazer o estímulo necessário para o atleta prosseguir, atingindo a autogratificação num nível mais alto. Atletas assim treinados, teriam um cérebro trabalhando contra uma resistência a autogratificação. E quando esta resistência fosse retirada, certamente este cérebro estaria com uma maior capacidade de produzir a autogratificação. Deste forma, atletas treinados consumindo diariamente café, caso parassem de tomá-lo na véspera e nos dias de competição, poderiam ter sua performance aumentada de forma significativa, sem qualquer tipo de "doping ". Apenas aumentando, além da capacidade dos músculos, a capacidade do cérebro de prosseguir mais além (ABIC, 2018).

Contudo, tudo que é consumido de forma excessiva pode se tornar prejudicial a saúde e com o café não seria diferente, o seu consumo de forma descontrolada pode causar 
males para o corpo humano, como aumento do nervosismo, tremores nas mãos, acelera os batimentos cardíacos, podendo também causar, aumento dos níveis de colesterol e contribuir para o intupimento das arterias, portanto é importante dosar tudo aquilo que se ingera e principalmente o café (EMBRAPA, 2011).

\section{CONSIDERAÇÕES FINAIS}

Apesar de o café, por muito anos, ser a bebida mais consumida no mundo e no Brasil, ainda há muitos preconceitos em seu entorno. Porém muitas pesquisas foram sendo desenvolvidas para mostrar o que realmente o café é e causa, fazendo com que o mesmo passasse de vilão a protetor da saúde humana (ABIC, 2018).

E com isso se pode analisar, que o consumo moderado da bebida pode prevenir e ajudar no desenvolvimento de algumas doenças, como depressão, diabete, câncer e outras.

Pois ele possui em seus componentes químicos muitos contribuintes, como, minerais, açúcares, ácidos, vitaminas, cafeína que ajudam nessa prevenção física e mental, abrangendo todas as faixas etárias.

Contudo, o seu consumo excessivo, pode causar males, como, nervosismo, tremores, níveis elevados de colesteróis, entre outros.

\section{REFERÊNCIAS}

Almeida, A. A. P. Café e saúde:três décadas de estudos. Revista Brasileira de Armazenamento, edição especial, n. 7, p. 56-63, 2003.

Arya, M.; Rao, J.M. An impression of coffe carbohydrates. Critical Reviews in Food Science and Nutrition 2007, p. 47 - 51.

Associação Brasileira Da Indústria De Café - ABIC. Disponível em:< http://www.abic.com.br/estatisticas.html >. Acesso em maio de 2018.

Bartutti, Ricardo. Café não provoca câncer (2016). Disponível em: $<$ http://jornal.usp.br/atualidades/cafe-nao-provoca-cancer-conclui-oms/>. Acesso em maio de 2018.

Belitz, H.-D.; Grosch, W.; Schieberle, P.; Food Chemistry, 4a. ed., Springer: Berlin, 2009. 
EMBRAPA. Café e saúde humana (2011). Disponível em:< https://ainfo.cnptia.embrapa.br/digital/bitstream/item/92424/1/cafe-doc-01.pdf >. Acesso em maio de 2018

Garrett, R.; Schmidt, E. M.; Pereira, L. F. P.; Kitzberger, C. S. G.; Scholz, M. B. S.; Erbelin, M. N.; Rezende, C. M. Discrimination of Arabica coffee cultivars by electrospray ionization Fourier transform ion cyclotron resonance mass spectrometry and chemometrics. LWT - Food Science and Technology 2013, p 50 496.

Joet, T.; Laffargue, A.; Descroix, F.; Doulbeau, S.; Bertrand, B.; Kochko, A.; Dussert, S. Influence of environmental factors, wet processing and their interactions on the biochemical composition of green Arabica coffee beans. Food Chemistry 2010, p 118693.

Krolow, Ana Cristina. Consumo do Café: benefício a saúde ou fator de risco (2011). Disponível em: $\quad<$ https://ainfo.cnptia.embrapa.br/digital/bitstream/item/59928/1/cafeAnaKrolow.pdf >. Acesso em maio de 2018

Lima, Darcy Roberto. Café melhora o desempenho no esporte e traz benefício à saúde (2013).

Disponivél em: $<$ http://www.consorciopesquisacafe.com.br/index.php/imprensa/noticias/425-cafemelhora-o-desempenho-no-esporte-e-traz-beneficio-a-saude>. Acesso em maio de 2018.

Lima, D. R. Café e composição química (2013). Disponível em: http://www.abic. com.br/café_composiçãoquimica.html. Acesso em maio de 2018.

Lima, D.R. (Editor): Café e Saúde: Manual de Farmacologia Clinica, Terapeutica e Toxicologia, Medsi Editora (3 volumes), RJ, 2003, págs 141-149.

Monteriro, M. A. M. D. S. Caracterização sensorial da bebida de café (Coffea arabica L.): análise descritiva quantitativa, análise tempo-intensidade e testes afetivos. Viçosa, 2002. Tese (Doutorado em Ciência e Tecnologia de Alimentos) - Universidade Federal de Viçosa.

Salva, G.J.T.; Lima, de. B.V. Composição química do café e as caracteristicas da

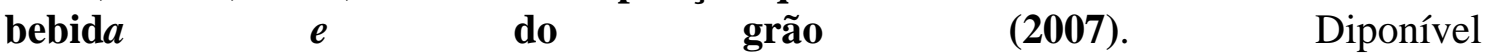
em:<http://www.iac.sp.gov.br/publicacoes/agronomico/pdf/v59_artigo13.pdf>. Acesso em maio de 2018.

Taveira, J. H. S.; Borém, F. M.; Rosa, S. D. V. F.; Oliveira, P. D.; Giomo, G. S.; Isquierdo, E. P.; Fortunato, V. A. Post-harvest effects on beverage quality and physiological performance of coffee beans. African Journal of Agricultural Research 2015, 10, 1457.

Trugo, L. Coffee . Em: Caballero, B., Trugo, L. Finglas, P. (Editores): Encyclopedia of Food Sciences and Nutrition (10 volumes), Academic Press, England, 2003, 2nd ed. 